\title{
A Brief Analysis of Status of Interaction Design in Industrial Design under the Background of Informatization
}

\author{
Hao Zheng ${ }^{1, a}$ \\ ${ }^{1}$ Department of art and design, Guangxi Vocational \& Technical College, Nanning, China, 530226 \\ a25512800@qq.com
}

\begin{abstract}
Keywords: Informatization; Interactive Design; Industrial Design
Abstract. With the continuous development of our economy and society, China has already stepped into the information age,which not only enlarged the scope of industrial design but also given rise to increasingly stronger dependence of industrial design on interactive experience among users. The interactive design, which has already exerted profound influence on people' s daily life, plays a crucial role in industrial design under the information era. This paper gives a study on the status of interaction design in industrial design for the purpose of further detailing of effects of interactive design.
\end{abstract}

\section{Introduction}

At present, China is undergoing rapid economic and social development, people are not easily satisfied with products with simple material functions and have higher requirements of the experience, emotional and spiritual satisfaction brought by products in use. Under such background of informatization, it's harder to meet users' requirements if the traditional industrial design principles are still adopted in product design and enterprise market competitiveness would decline. In the case of the present threat concerning survival of enterprises, some designer pioneer combine principles involving interaction design in the field of computer with industrial design and establish the user-centered and experience-oriented product design mode, under which,the series of requirements of users are better met. From this we can see that interaction design has an important status in industrial design under the background of informatization.

\section{Significance of the Study}

From the perspective of the study in this paper, the author divide the products into two categories, namely technology-driven products and user-driven products, among which, the former kind of products attract consumers by their powerful technology and the latter kind of products center on user experience and keep users by good interaction experience. Because the existing technical barriers in China are getting weaker and weaker, technology-driven products are becoming less and less attractive to consumers. In order to solve the problem, interaction design shall be applied in technology-driven products. Thus, it is indicated that, interaction design plays an important role in industrial design under the background of informatization[1].

\section{Overview of Product Interaction design}

\subsection{Definition of interaction design}

With the continuous development of the times,, interaction design has already separated itself from simple computer interface design and the current and introduced into the filed of industrial design. Besides, almost all the products $n$ providing interaction with people fall into the category of interaction design. Table 1 gives a derailed description of the two stages of the interactive behaviors between users and products. It is indicated clearly that, the process of using products is the interaction set composed of the interactive behaviors between users and products[2].

Table 1 Interactive Behavior between Users and Products 


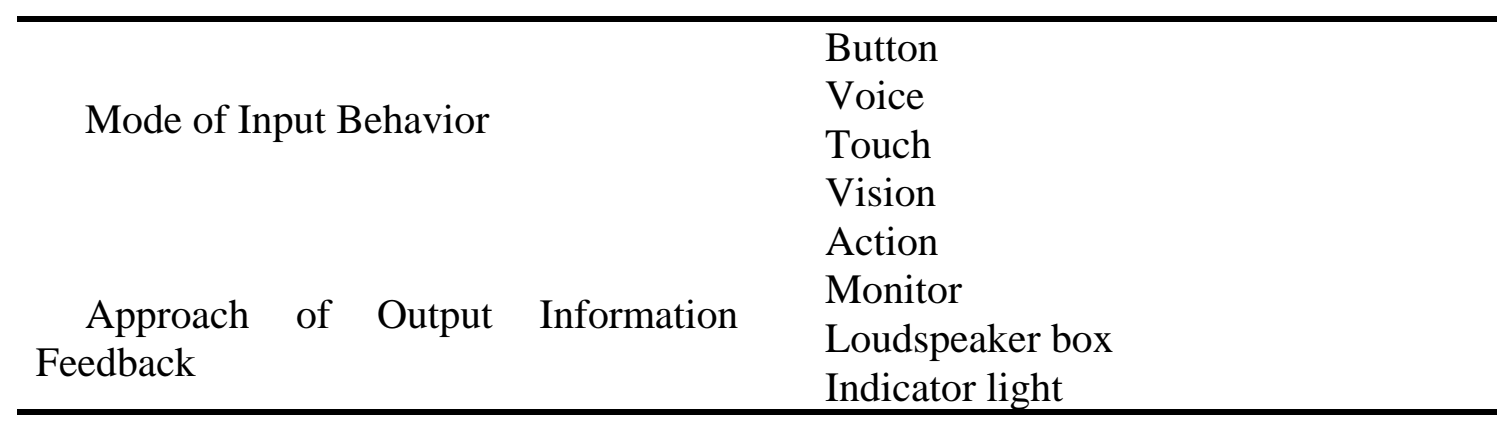

As a new inter-discipline, interaction design is mainly targeted at meeting users' needs and providing easy-to-use products. In this paper, the author divides the interaction design into the three elements of user, media and process in light of focus of the study. Table 2 intuitively describes the role of the three elements in interaction design. And with Table 2, we can see that application of the three elements in interaction design can truly realize design of product bringing users good experience. In this case, we can ensure that products provide better user experience and avoid the commonly-seen problems that users have to get used to the product in tradition product design[3].

Table 2 The Role of Three Elements of User, Media and Process in Interaction Design

\begin{tabular}{|c|c|}
\hline Element & Role \\
\hline User & $\begin{array}{l}\text { Determining the starting and ending } \\
\text { point of the interaction procedures and } \\
\text { playing a leading role in interaction design }\end{array}$ \\
\hline Medium & $\begin{array}{l}\text { Medium is the undertaker of interactive } \\
\text { behaviors ,mobile phone, television, } \\
\text { microwave oven and other appliances } \\
\text { used in daily life are important media of } \\
\text { interactive behaviors. }\end{array}$ \\
\hline Process & $\begin{array}{l}\text { Purposeful actions of users on the } \\
\text { media and the actions to realize goals of } \\
\text { the users with certain medium are called } \\
\text { as the process element of the interaction } \\
\text { design. }\end{array}$ \\
\hline
\end{tabular}

\section{Application of Interaction Design in Industrial Design}

Under the background of informatization, the most common methods adopted in combination of interaction design and industrial design include interaction design driven by users' goals and users' behaviors . In order to give a better study on status of interaction design in industrial design under the background of informatization, the author gives detailed discussion on the two design methods.

3.1 Interaction design method driven by users' behaviors

As to the interaction design method driven by users' behaviors, in which, users' behaviors are used as the first elements.For this reason, designers usually pay more attention to the behaviors of people while using the product in the process of product design, which is fundamentally different from the traditional high importance paid to product itself.In specific application of interaction design method driven by users' behaviors, following procedures shall be conducted successively: setting of user model. analysis of user model behaviors, product prototype construction, usability test of the prototype, scheme iteration and improvement, and design output. Table 3 gives clear description of main contents of the series of procedures. Through all these procedures, designers can make sure the interaction design driven by users' behaviors more practicable and advanced [4].

Table 3 Procedures of Interaction Design Method Driven by Users’ Behaviors

Stages of interaction design driven by Specific Measures




\begin{tabular}{|c|c|}
\hline \multicolumn{2}{|l|}{ users' behaviors } \\
\hline & target users \\
\hline Stage of user model setting & $\begin{array}{l}\text { establishing user model with view to } \\
\text { characteristics of the target users; the user } \\
\text { model shall be used to reflect users' true } \\
\text { behavior characteristics. }\end{array}$ \\
\hline $\begin{array}{l}\text { Analysis stage of behavior pattern of } \\
\text { user model }\end{array}$ & $\begin{array}{l}\text { Analyzing the behavior in using } \\
\text { products and characteristics of user } \\
\text { groups based on the user model } \\
\text { established in the previous stage; the } \\
\text { analysis can be conducted by observation, } \\
\text { in-depth interview, focus group and scene } \\
\text { survey methods. }\end{array}$ \\
\hline $\begin{array}{l}\text { Stage of product prototype } \\
\text { construction }\end{array}$ & $\begin{array}{l}\text { Reaching the scheme for analysis of } \\
\text { users' behavior characteristics with the } \\
\text { user model to check for feasibility of the } \\
\text { scheme based on materialization and } \\
\text { visualization of the products. }\end{array}$ \\
\hline Utility test of product prototype stage & $\begin{array}{l}\text { In order to determine whether the } \\
\text { product prototype can meet users' needs, } \\
\text { scene investigation method is adopted by } \\
\text { inviting a certain number of users and } \\
\text { asking them to complete } 5 \text { typical } \\
\text { characters, thus we can finish test of the } \\
\text { product prototype according to the extent } \\
\text { of completion of the } 5 \text { characters. }\end{array}$ \\
\hline $\begin{array}{l}\text { Scheme iteration and improvement } \\
\text { stage }\end{array}$ & $\begin{array}{l}\text { The usability test of the prototype is } \\
\text { repeated for several times to solve all } \\
\text { problems concerning the interaction. }\end{array}$ \\
\hline Design output stage & $\begin{array}{l}\text { Actual design of appearance, structure, } \\
\text { software and technology used in the } \\
\text { product prototype until the physical } \\
\text { product is put into use. }\end{array}$ \\
\hline
\end{tabular}

3.2 Interaction design method driven by users' goals

The interaction design method driven by users' behaviors has some similarities to the interaction design method driven by users' goals for both the two methods give emphasis on the steps such as user model, concept design, and test modification, which help truly realize integration of integration design principles in industrial design.As to interaction design method driven by users' goals mainly embraces in six stages, namely research, modeling, framework establishment, determination of needs, detailing,and test modification. However, no further explanation on this method is given for it is of some similarity to the design method driven by users behaviors. The two methods are not in conflict with each other and, if combined, the two methods can achieve better effect, to which, we shall attach importance[6].

\section{Status of Interaction Design in Industrial Design}

Under the background of informatization, application of interaction design in industrial design brings better emotional experience and user experience and enhances purely subjective feelings of users during usage of products. In the information era, products and services provided by enterprises are not targeted at individuals any longer but huge and complicated subject. For this reason, the purely subjective feeling of users come to exert the most direct impact on selling and promotion of products. In such case, application of interaction design principles in industrial design can be 
regarded as the "timely rain" for work concerning this field and it helps avoid the problem of industrial design failing to meet users' requirements from being more serious. Therefore, the author concludes that interaction design plays a leading role in the present industrial design in China under the background of informatization and directly influences selling and user experience of the products, and concerns survival of the enterprises as well.Hence, Chinese modern enterprises shall pay high importance to application of interaction design in industrial design so that they can realize long-term sustainable development.

\section{Conclusion}

Through the study in this paper, the author reaches the following conclusions: first, interaction design plays a leading role in industrial design under the background of informatization and decisively influences the effect of industrial design. Thus, we can see that interaction design is of vital importance and accordingly Chinese enterprises have to apply interaction design principles in process design of products so as to gain certain share in the fiercely competitive market.

\section{References}

[1]Vertegaal R. The (re)usability of everyday computational things: why industrial design will be the new interaction design[J]. Interactions, 2011, 18(1):38-41.

[2]Mackenzie I S. Fitts' Law as a Research and Design Tool in Human-Computer Interaction[J]. Human-Computer Interaction, 1992, 7(1):91-139.

[3]Mackenzie I S. Fitts' Law as a Research and Design Tool in Human-Computer Interaction[J]. Human-Computer Interaction, 1992, 7(1):91-139.

[4]Ross P, Keyson D V. The case of sculpting atmospheres: towards design principles for expressive tangible interaction in control of ambient systems[J]. Personal \& Ubiquitous Computing, 2007, 11(2):69-79.

[5]Balesdent M, Bérend N, Dépincé P, et al. A survey of multidisciplinary design optimization methods in launch vehicle design[J]. Structural \& Multidisciplinary Optimization, 2012, 45(5):619-642.

[6]Huang S H, Yang Y I, Chu C H. Human-centric design personalization of 3D glasses frame in markerless augmented reality[J]. Advanced Engineering Informatics, 2012, 26(1):35-45. 